\title{
DIMENSÕES E LÓGICAS DO ARRENDAMENTO RURAL NA AGRICULTURA FAMILIAR: UM ESTUDO DE CASO
}

Luís Felipe Perdigão de Castro*

RESUMO: A partir de dados dos Censos Agropecuários (1995 e 2006), à luz da interpretação econômica e sociológica do Direito, pesquisam-se elementos relacionados às opções de arrendamento rural, em estudo de caso no município de Rio Verde (GO). O objetivo é investigar como a decisão sobre acessar terras, pela via contratual (arrendamento rural), é uma decorrência do "habitus" da categoria social, interpretado como dimensões e lógicas do processo decisório. Foca-se na formação dos arrendamentos rurais no contexto da agricultura familiar, bem como no "habitus" dessa categoria social, enquanto fator central para a decisão de acessar terras através do arrendamento em Rio Verde (GO).

PALAVRAS-CHAVE: Acesso à terra; Agricultura familiar; Arrendamentos; Habitus.

\section{DIMENSIONS AND LOGIC OF RURAL LEASING IN FAMILY AGRICULTURE: A CASE STUDY}

ABSTRACT: Factors related to rural leasing options are researched by investigating a case study in the municipality of Rio Verde GO Brazil, from data produced by the Agricultural and Livestock Censuses (1995 and 2006) and seen through an economic and sociological interpretation of Law. Accessing land by rural leasing follows the "habitus" of the social category interpreted as dimensions and logic of the deciding process. The formation of rural leasing and the category's "habitus" within the context of family agriculture are highlighted as a central factor for the decision to access agricultural land through leasing in Rio Verde, Brazil.

KEY WORDS: Access to land; family agriculture; leasing; Habitus.

Doutorando em Ciências Sociais, pelo Departamento de Estudos Latino-Americanos (CEPPAC/ UnB), da Universidade de Brasília (UnB); Docente (Mestre I) do Centro Universitário de Desenvolvimento do Centro Oeste - UNIDESC e nas Faculdades Integradas da União Educacional do Planalto Central - FACIPLAC; Vinculado aos seguintes grupos de pesquisa da UnB: MeCACB, LEIJUS, BICAS e Estudos Comparados de Sociologia Econômica. Advogado (OAB/DF). Brasil; E-mail: Ifperdigao@gmail.com 


\section{INTRODUÇÃO}

A temática dos arrendamentos ruraisé, por sua natureza e formação histórica, objeto de estudos multidisciplinares. Nesse sentido, a dinâmica do campo brasileiro ultrapassa a visão de espaço estritamente agropecuário e revela consigo uma série de discussões sobre acesso à terra, reprodução social das categorias sociais, formas de viver a agir em relação à terra e, especialmente, os desafios da desigualdade de recursos, poder e terra entre sujeitos políticos (CASTRO; SAUER, 2012).

Das modalidades de acesso à terra admitidas no Brasil, os arrendamentos rurais são os menos utilizados (IBGE, 2007), ficando atrás da propriedade (direito real), da ocupação (direito de posse direta) e da parceria (direito contratual de uso temporário). Considerando esse rol de formas de acesso, a literatura de juristas agraristas, economistas e sociólogos sustenta teses de que os arrendamentos rurais seriam contratos que melhoram o acesso à terra pelos mais pobres (CASTRO, 2013). Porém, o que instiga é que os dados censitários apontam baixos índices de arrendamento no Brasil (IBGE, 2007). Portanto, existe uma peculiaridade no caso brasileiro que consiste em termos alta concentração fundiária, com grande número de trabalhadores com pouca ou nenhuma terra e, mesmo assim, os arrendamentos não serem uma via alternativa para o acesso à terra (CASTRO, 2013).

Diante de tal complexidade, o presente artigo analisa os elementos condicionantes dos arrendamentos rurais na Agricultura Familiar brasileira. $\mathrm{O}$ objetivo é identificar as condicionantes e sua dinâmica à luz do "habitus". Direcionase, como objetivo específico, o estudo teórico a uma discussão sobre os resultados do trabalho de campo, realizado no município de Rio Verde, Estado de Goiás. Metodologicamente, o levantamento de informações ocorreu através de entrevistas em profundidade, com ênfase na análise qualitativa das narrativas e discursos, sobre uma amostra não probabilística (de conveniência), representativa do objeto pesquisado. $^{2}$

Sendo assim, o presente trabalho expõe um breve panorama conceitual,

2 Este artigo é parte da pesquisa desenvolvida pelo autor, em sede de mestrado no Programa de Pós-Graduação em Agronegócios (PROPAGA), da Universidade de Brasília (UnB), sob orientação do Prof. Dr. Sérgio Sauer e financiamento do Conselho Nacional de Desenvolvimento Científico e Tecnológico (CNPq). Atualmente, encontra-se em aprofundamento, como projeto de tese de doutoramento do autor, no Centro de Pesquisa e Pós-Graduação sobre as Américas (CEPPAC/UnB), da Universidade de Brasília (UnB). Tais informações se prestam a esclarecer que, apesar dos resultados do trabalho de campo, o tema desafia novos estudos e uma compreensão comparada sobre a prática contratual na América Latina. 
delimitando definições fundamentais à compreensão da pesquisa, tais como acesso à terra, agricultura familiar e "habitus". Na sequência, investigam-se elementos econômicos e sociais que condicionam de forma mais genérica os contratos agrários. Em seguida, discute-se a percepção e as configurações de contratos. A partir do diálogo entre essas condicionantes, foca-se na forma com que o "habitus" influencia o processo decisório, tomando por base o trabalho de campo realizado em Rio Verde (GO).

1.1 REFERENCIAIS TEÓRICOS: ACESSO À TERRA, AGRICULTURA FAMILIAR E "HABITUS"

O acesso à terra rural é um direito humano, que se destaca como necessário à realização plena de uma série de outros direitos. Nesse sentido, o acesso à terra é um direito humano aglutinador e viabilizador de outros preceitos constitucionais básicos, como a vida e a dignidade humana. Para melhor compreensão, tomemos por exemplo a relação entre os direitos de acesso à terra e de alimentação adequada (CASTRO, 2015a, p. 93).

Alimentar-se adequadamente é um direito humano com bases jurídicas na Declaração Universal dos Direitos Humanos e recepcionado na Constituição Federal de 1988. Enfatiza-se que o direito de se alimentar não ocorre somente através de sistemas de distribuição, processamento e venda de alimentos, mas também pelo acesso à terra. Dentre os principais dispositivos constitucionais que colocam o acesso à terra rural como direito humano e fundamental está o princípio da função social da propriedade. Ele especifica que a função social é cumprida quando a propriedade rural atende, simultaneamente, aos requisitos do artigo 186, da Magna Carta de 1988 (CASTRO, 2015a).

Além disso, a Constituição Federal reconheceu o direito de acesso à terra quando se referiu a povos indígenas e outras comunidades tradicionais, mediante direitos especiais sobre territórios. Tais direitos estão assegurados em tratados internacionais como a Convenção 169 da OIT (Organização Internacional do Trabalho), aprovada pelo Decreto Legislativo 143, de junho de 2002. Por esse viés, 
a Constituição, em seu artigo 231, assegura aos índios o direito sobre as terras que tradicionalmente ocupam. Além dos povos indígenas, as comunidades quilombolas também possuem o direito constitucionalmente garantido ao território, previsto na Constituição Federal no artigo 68 das Disposições Transitórias (BRASIL, 1988).

Embora a Constituição Federal não tenha dado à agricultura familiar um tratamento específico no tocante ao acesso à terra, esse direito está profundamente relacionado à existência e formas de reprodução social da categoria. Nesse sentido, a agricultura familiar é o principal ator social para a garantia do direito humano à alimentação adequada, este previsto (desde 2010) na Constituição da República.

Contudo, a importância de se discutir o direito de acesso à terra como direito humano, no âmbito da agricultura familiar, não diz respeito apenas à segurança alimentar. Liga-se também a novas formas de se propor o desenvolvimento, na medida em que essa categoria social evidencia formas de viver e agir peculiares, isto é, apresenta uma interação própria entre família, produção agrícola e meio ambiente (SAUER, 2003; 2008).

O termo agricultura familiar, neste trabalho, recupera o pensamento de Wanderley (1999; 2009a; 2009b), para quem a conceituação assume ares de novidade, designando conceitos já enraizados na sociedade brasileira como o tradicional camponês, agricultor de subsistência e pequeno produtor rural e incorpora, conceitualmente, os desafios da modernidade. A agricultura familiar, que se reproduz nas sociedades modernas, deve adaptar-se a um contexto socioeconômico próprio dessas sociedades, as quais levam a modificações importantes nas formas de vida social tradicionais (WANDERLEY, 1999; 2009a; 2009b; CASTRO; SAUER, 2012; CASTRO, 2015b, p. 04).

Essas transformações não significam, contudo, uma ruptura total e definitiva com as formas anteriores, devendo o agricultor familiar moderno adaptarse às novas exigências da sociedade, sem desvincular-se das tradições camponesas (WANDERLEY, 1999; 2009a; 2009b). Segundo Sauer (2008), na luta pela terra, enquanto resistência aos processos de dominação e exclusão, termos como agricultura familiar e agronegócio surgem enquanto conceitos-síntese ou mais que simples categorias empíricas, à medida que teriam uma construção, apropriação e uso voltados para a expressão de identidades sociais. Nesse contexto, a agricultura familiar pode ser caracterizada a partir dos seguintes elementos: 
a) a gestão da unidade produtiva e os investimentos nela realizados são feitos por indivíduos que mantém entre si laços de sangue ou casamento; b) a maior parte do trabalho é igualmente fornecida pelos membros da família; c) a propriedade dos meios de produção (embora nem sempre da terra) pertence à família e é em seu interior que se realiza sua transmissão em caso de falecimento ou aposentadoria dos responsáveis pela unidade produtiva (INCRA/FAO, 1996, p. 4).

Do ponto de vista legal, com um viés mais operacional, a Lei 11.326, de 24 de julho de 2006, definiu o agricultor familiar como aquele:

[...] que pratica atividades no meio rural, atendendo, simultaneamente, aos seguintes requisitos: I - não detenha, a qualquer título, área maior do que 4 (quatro) módulos fiscais; II - utilize predominantemente mão-de-obra da própria família nas atividades econômicas do seu estabelecimento ou empreendimento; III - tenha renda familiar predominantemente originada de atividades econômicas vinculadas ao próprio estabelecimento ou empreendimento; IV - dirija seu estabelecimento ou empreendimento com sua família (BRASIL, 2006).

Embora essas definições pareçam bem delimitadas, o termo agricultura familiar se consolida e se difunde nos diferentes setores da sociedade, como um guarda-chuva conceitual, que abriga grande número de situações, em contraposição à agricultura patronal, tendo como ponto focal da polarização o tipo de mão de obra e de gestão empregadas (NEVES, 1995). Contudo, para o objeto desta pesquisa, interessa investigar abordagens que dão espaço à reflexão sobre a complexidade da lógica intrínseca à agricultura familiar, "apontando para a importância das afiliações socioculturais dos grupos sociais, isto é, seu modo de ver as coisas" (CHALITA, 2005b, p. 9).

Por esse caminho, as concepções de mundo são produtos do sujeito, mas também de um agregado de situações provenientes de sua categoria social, ao longo de todo um trajeto histórico. Essas relações podem ser interpretadas a partir da dinâmica de um "habitus" no espaço social (BOURDIEU, 2008b). Segundo Bourdieu (2008b, p. 162-164), essa dinâmica ocorre pela existência do "habitus", isto é, um conjunto de disposições gerais e transponíveis - socialmente construídas e incorporadas - que fazem com que o conjunto de práticas, uma vez produto de condições sociais semelhantes, adquira um caráter sistemático e, da mesma forma, 
sejam sistematicamente distintos de outras. É a "interiorização da exterioridade e a exteriorização da interioridade" (CATANI, 2002, p. 111).

A formação e o desenvolvimento da agricultura familiar seguem a lógica de reprodução da vida social, envolvendo tanto a mudança de algumas estruturas quanto a permanência de outras (WANDERLEY, 1999). É um processo dinâmico, não implica na perpetuação imutável de uma realidade, mas se dá em meio a transformações e adaptações, marcadas pela produção e reprodução das condições de sobrevivência, através de estratégias (BOURDIEU, 1992, p. 114).

A estratégia é o resultado da articulação de um "habitus", que é essa espécie de senso prático do que se deve fazer em dada situação. As estratégias de reprodução se manifestam como elementos dinâmicos de adaptação e mudança na perpetuação social de seu universo e de sua identidade (LAMARCHE, 1993; 1994; WANDERLEY, 1996; BRANDEMBURG, 1999) e, por extensão, norteiam as opções de acesso à terra, através da propriedade, posse, ocupação ou por formas contratuais, dentre elas, o arrendamento rural. Algumas das estratégias de reprodução da agricultura familiar, como a partilha da herança, a organização do trabalho familiar, a escolarização dos filhos (LAMARCHE, 1993) ou a pluriatividade (WANDERLEY, 1999; FERREIRA, 2002) estão diretamente relacionadas com o juízo de oportunidade e conveniência que o agricultor forma no momento de decidir se deve ou não arrendar.

Por fim, outras estratégias, ligadas à matéria contratual, têm sido estudadas e mostram os esforços desses agricultores em se viabilizarem como tal, como a integração de produção junto a indústrias (PAULILO, 1990), formas de associativismo e cooperação (FERREIRA, 1995) ou a formação de contratos híbridos (CASTRO, 2013). Todas essas estratégias constituem respostas dos agricultores aos desafios gerados pelos bloqueios históricos.

\section{MATERIAL, MÉTODOS E RESULTADOS}

A pesquisa objetivou compreender as condicionantes do arrendamento rural na Agricultura Familiar. Com esse intuito, realizamos entrevistas em profundidade com vinte pessoas de Rio Verde (GO). Como método para coleta, o levantamento 
de informações ocorreu através da realização de entrevistas em profundidade. Esse recurso metodológico consiste em conversas face a face, permitindo que se explore e aprofunde a investigação, descrevendo processos e fluxos, com vistas a analisar, discutir e fazer prospectivas (MARCONI; LAKATOS, 2005). Assim, obtivemos o rol preliminar de entrevistados que, de forma mais ou menos aproximada, retrataram os perfis da agricultura familiar brasileira, conforme as tipagens de Baiardi (1999). Foram entrevistados 20 (vinte) agricultores, sendo 16 (dezesseis) agricultores familiares, dentre os quais 8 (oito) provenientes de áreas de assentamento de reforma agrária e 8 (oito) de propriedades particulares. Outros 4 (quatro) entrevistados são provenientes da agricultura não familiar, ligados a empreendimentos agroindustriais de Rio Verde.

Foram realizadas entrevistas sobre uma amostra não probabilística (de conveniência), representativa do objeto pesquisado, com o intuito de captar as percepções dos agricultores familiares em relação ao arrendamento rural, utilizando as visões complementares de agricultores não familiares para enfatizar peculiaridades valorativas. Para obter tais informações, optamos por Rio Verde (GO), um município inserido no Sudoeste de Goiás, reconhecido por uma estrutura agroindustrial altamente organizada (FETAEG, 2002; IBGE 2006). Do ponto de vista do acesso às comunidades e aos perfis socioculturais, há presença de cooperativas agrícolas, com diferentes públicos. Para melhor elucidação do universo geográfico, segue o mapa da região:
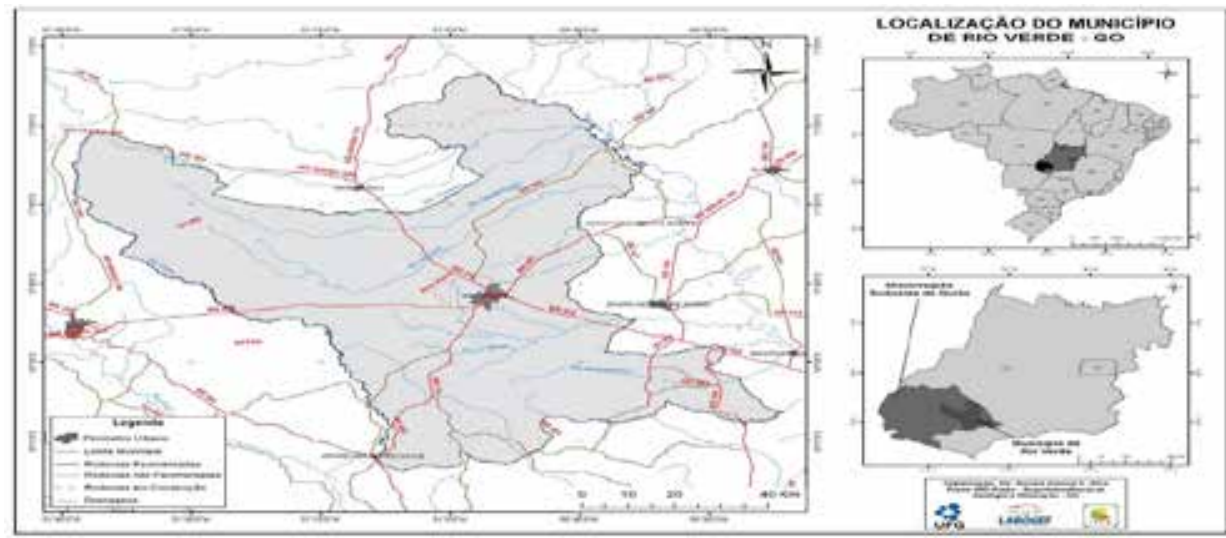

Mapa 1. Estado de Goiás e Município de Rio Verde 
Os dados obtidos permitiram a sistematização de três (3) subgrupos, através da autodenominação, adequação ao conceito legal-operacional da Lei 11.326/06 e análise das relações internas de seus integrantes. Dessa forma foi possível sintetizar o perfil dos entrevistados para compreender o processo decisório segundo características elementares da categoria social (CASTRO, 2013, p. 96-99).

No subgrupo 1 identificamos pessoas que se definiram como "agricultores familiares". No subgrupo 2, os entrevistados se identificaram como "pequeno proprietário", "agricultor menor" ou mesmo "lavrador". Já as pessoas do terceiro subgrupo se autodefiniram como "empresário", "empresário rural", "empreendedor rural" ou ainda "arrendatário" ligado a grandes empreendimentos agroindustriais (CASTRO, 2013, p. 96-99). Todas as pessoas do subgrupo 1 se enquadraram perfeitamente na definição legal de agricultor familiar, enquanto nenhum integrante do subgrupo 3 pode ser, do ponto de vista legal, considerado agricultor familiar. Ou seja, nesses casos, houve uma convergência entre autodenominação e enquadramento legal.

No subgrupo 2 constatamos uma peculiaridade: os agricultores não se autodenominaram "familiares", embora o fossem nos termos da Lei 11.326/06. Nesse subgrupo estão agricultores em grave descapitalização e outros que já deixaram suas terras. Os que ainda permanecem tendem a deixar de se enquadrar na acepção legal do termo, pois o trabalho externo (urbano) vem assumindo importância crescente na subsistência da família (CASTRO, 2013).

Tanto no subgrupo 1, quanto no 2, predomina a mão de obra familiar, contudo, em contextos muito distintos. No subgrupo 1, a mão de obra familiar tende a ser complementada por vizinhos e contratações eventuais, para incrementar e expandir a capacidade da unidade. Já no subgrupo 2 a dinâmica é inversa, pois ocorre uma progressiva saída de familiares da propriedade, fazendo com que a mobilização dos esforços laborais diminua e a unidade seja cada vez menos responsável pela subsistência e trabalho da família. Por sua vez, o subgrupo 3 apresenta uma organização empresarial do trabalho (contratações formais e celetistas).

Tal sistematização simplificou o perfil dos entrevistados e, ao mesmo tempo, ressaltou (pela diferenciação) algumas características elementares da agricultura familiar. As diferenças de linguagens, representações e valores evidenciaram 
vínculos mais profundos entre as pessoas de um mesmo subgrupo (espaço social), expondo formas de agir e viver que manifestam o significado da terra, a importância da família, as limitações legais para as atividades desenvolvidas, a transmissão de saberes, as relações de trabalho, etc.

A articulação desses elementos ocorre na dinâmica do "habitus", isto é, através de um diálogo constante entre realidades subjetivas e objetivas. Para tornar esse diálogo mais acessível à pesquisa, os dados foram organizados a partir de dimensões e lógicas, tidas como estruturas estruturantes do processo decisório sobre se tornar um arrendatário ou arrendador rural (CASTRO, 2013).

A "dimensão teleológica" abarca as finalidades que o agricultor confere a certas coisas, dentre elas a terra. A terra não é somente um recurso produtivo, mas, antes de tudo, é lar, canto, cantinho, cuja missão é produzir para o bem de todos (família e comunidade). Entre os agricultores familiares assentados, a terra é fruto de luta e resistência, razão pela qual assume um significado político e cultural muito forte (conquista coletiva e realização de um sonho) (CASTRO, 2013, p. 115-118)

$\mathrm{Na}$ "dimensão legal" se inserem elementos atinentes à percepção do Direito e desdobramentos de caráter extrajurídico. A vedação do arrendamento em certas áreas (assentamentos de reforma agrária) e a preocupação em mostrar que são pessoas honestas e honradas é uma valoração recorrente, que permeia a concepção de "cumprir a lei". Nesse sentido, realizar o arrendamento rural nessas áreas é visto como algo errado, ruim e que compromete a honra da comunidade, pois coloca o agricultor na delicada situação de perder a posse da terra por ato ilícito. Ou seja, independente do teor do contrato e seus objetivos, menciona-se o argumento legal contra a prática (CASTRO, 2013, p. 118-121).

Por outro lado, a busca por legalidade também representa uma forma de externar o respeito à finalidade da terra, negando a pretensão de vender ou desviar seu uso, no caso de agricultores familiares assentados. Em relação aos agricultores familiares tradicionais, e mesmo para os assentados, a dimensão legal não se esgota

3 Para os agricultores familiares entrevistados, em geral, a terra é meio e fim, pois nela e por ela se realizam coisas da vida, como o trabalho, moradia e alimentação. Através dessas significações, o contrato de arrendamento rural foi visto, pela maior parte dos entrevistados, como um acordo eminentemente comercial. Para eles, dispor sobre a terra (através do arrendamento rural) não é simplesmente alugar terras, mas negociar aquilo que lhes é central para organização e sobrevivência da família. As finalidades e significações atribuídas à terra tornam seu uso e fruição um bem da e para a família, que dificilmente é posto sob livre comercialização (CASTRO, 2013, p. 115-135). 
na ideia de ser dono (direito real de propriedade). Não basta ser dono, é preciso estar em conformidade com o direito para ser reconhecido, respeitado e ter visibilidade perante a família e a sociedade. Por esse viés, o contrato de arrendamento é tido como um negócio arriscado, à medida que pode gerar dívidas, procedimentos e processos judiciais que abalam o patrimônio moral e afetivo que o agricultor sustenta do ponto de vista pessoal e formal-jurídico (CASTRO, 2013).

$\mathrm{Na}$ "dimensão sociocultural" predomina uma série de preocupações com a reprodução social da família. O foco dos agricultores familiares entrevistados é a reprodução de suas formas de agir e viver, o que inclui garantir a posse da terra. Nesse sentido, o arrendamento rural é visto como um contrato que, por ser limitado no tempo, não dá a posse definitiva da terra para que a família garanta o horizonte das gerações, com uma organização própria do tempo e do espaço. A questão da posse repercute também sobre a autonomia que o agricultor necessita para gerir suas atividades. A seu ver, o arrendamento rural não dá liberdade suficiente para agir conforme as necessidades da família, afinal, existem cláusulas pré-definidas para uso, fruição e produção. Ou seja, os entrevistados (agricultores familiares) percebem o arrendamento rural como incompatível com o desejo de trabalhar para si, organizando o tempo e o espaço ao modo da família (CASTRO, 2013, p. 121-124).

Em suma, da combinação das "dimensões teleológica, legal e sociocultural", o arrendamento rural é percebido pelos entrevistados como um contrato de caráter fortemente comercial, arriscado (do ponto de vista legal e econômico) e de posse temporária, não sendo um mecanismo ou instrumento suficiente para garantir o acesso à terra como lugar de trabalho e de vida (CASTRO, 2013).

Essa percepção traz implicações práticas para o contrato, através de lógicas que dizem respeito à operacionalização das avenças. Exemplo disso é o fato do contrato ser visto como um acordo a ser firmado entre parentes, amigos, conhecidos de culto religioso ou associações, para os quais a terra assume um significado especial e compartilhado. Os laços sociais entre os contratantes são decisivos, pois permitem que o contrato surja e se desenvolva em uma relação de iguais (baseada na "boa vizinhança").

Essa proximidade no espaço social não denota somente uma lógica social, mas viabiliza também a existência de contratos híbridos. Identificamos a criação de 
arrendamentos rurais com forte tendência à parceria (partilha de riscos e despesas), evidenciando uma lógica técnico-contratual peculiar. Trata-se da combinação de dois aspectos: a) o arrendamento rural apresenta a figura do arrendador, do arrendatário, da renda e da cessão do uso (arrendamentos verdadeiros); e b) a execução contratual é permeada por benefícios e obrigações que extrapolam as partes contratantes, formando contratos em teia, com familiares e conhecidos.

Além disso, o quantitativo de mão de obra disponível na unidade é outro fator que incide sobre a decisão. Ou seja, os agricultores familiares entrevistados só decidem pelo arrendamento rural, ainda que híbrido, na medida em que os braços da família são suficientes para agregar novas áreas e o risco de endividamento está sob controle. Por outro lado, a resistência em deixar suas terras para se tornar arrendador evidenciou uma lógica cultural que compõe o processo decisório, sob a ótica das afetividades da família. A terra é, sobretudo, o lugar das afetividades, daquilo que "não tem preço".

\section{DISCUSSÃO: PERCEPÇÕES E CONFIGURAÇÕES DA PRÁTICA}

Os materiais (narrativas e discursos) provenientes das entrevistas em profundidade nos permitem avaliar que, diante do que a terra significa para $o$ agricultor familiar, os contratos de arrendamento rural são vistos pelos entrevistados como instrumentos muito limitados para incluir cláusulas que conciliem a terra enquanto recurso produtivo, espaço geográfico e simbólico (CASTRO, 2013, p. 124152).

A resistência é mais baixa com relação a se tornar arrendatário, pois os entrevistados viram nessa posição contratual uma menor chance de perdas, especialmente afetiva (deixar a terra). Alguns avençaram a possibilidade de acessar novas áreas para cultivos mais rentáveis como a soja e o sorgo. Esses entrevistados manifestaram o desejo de serem arrendatários de terras próximas às suas, de pessoas conhecidas e em pequenas dimensões (até 15 hectares). Contudo, alegaram que arrendar terras de agricultores não familiares é uma possibilidade muito remota em Rio Verde, pois a maior parte dos proprietários procura firmar contratos formais, 
com adiantamentos de renda e garantias reais, que não estão condizentes com a realidade dos agricultores familiares entrevistados. ${ }^{4}$

Dessa forma, os fatores condicionantes do arrendamento podem ser postos considerando quatro situações (padrões derivados da legislação vigente): "Configuração 1": Agricultor Familiar (Arrendatário) contrata com Agricultor Familiar (Arrendador); "Configuração 2": Agricultor Familiar (Arrendador) contrata com Agricultor Familiar (Arrendatário); "Configuração 3": Agricultor Familiar (Arrendatário) contrata com Outra categoria social (Arrendador); "Configuração 4": Agricultor Familiar (Arrendador) contrata com Outra categoria social (Arrendatário).

Dentre as hipóteses de relações contratuais acima, o agricultor familiar pode ser arrendatário de terras, no contexto em que contrata com outro agricultor familiar (parte arrendadora). Nessa situação, as percepções sobre os fatores determinantes para o arrendamento rural foram os seguintes:

a) Haver mão de obra disponível na família do arrendatário, para cultivar novas terras;

b) Haver vínculos afetivos e sociais entre arrendante e arrendatário, especialmente com parentesco familiar, visando relações de confiança para que o contrato contenha menor formalidade (oralidade ou registro cartorial simples), além de equalizar o poder de barganha (relações entre iguais, sem cunho meramente comercial, para fixar a renda). Nesses casos, é muito comum que a casa de um dos agricultores, a sede da cooperativa ou o templo religioso sejam ambientes nos quais os contratos são solenizados;

c) Outro item é haver proximidade física das glebas a serem arrendadas, dando a perfeita noção de que há continuidade entre as áreas. Isso diminui os custos com distância (circulação/transporte da família, animais e máquinas, cercas e vigilância) e, ainda, viabiliza o trabalho conjunto da mão de obra, além de manter uniforme a porção territorial que a família atua. Essa proximidade física também é vista como uma forma legítima do agricultor familiar arrendador fiscalizar o bom uso das terras (CASTRO, 2013, p. 124-152).

\footnotetext{
4 Nesse discurso, o ambiente altamente seletivo e competitivo tem caráter excludente, reforçado pela representação de que o arrendamento é um contrato típico dos grandes empreendimentos agrário-capitalistas. Há uma desconstrução do arrendamento rural, no âmbito da percepção, como alternativa de acesso à terra e o termo "arrendatário" passa a ser sinônimo de "empresário rural". Essas repercussões contratuais permitem compreender quando o processo decisório do agricultor familiar se aproxima ou se distancia da conclusão de um contrato de arrendamento rural.
} 
Além desses fatores, somam-se outros ${ }^{5}$, tais como: haver similaridade nas características naturais da área arrendada (solo, vegetação, recursos hídricos, inclinação do terreno) diminuindo a possibilidade do fator surpresa com pragas, correções de solo e irrigação (considerados de alto custo social, pois demandam mais trabalho da família e comprometem a produção de subsistência e comercial, além de exigirem gastos extras com serviços, insumos, agrotóxicos e maquinário) (CASTRO, 2013, p. 124-152).

Porém, como as relações contratuais são dinâmicas, o agricultor familiar pode ser arrendatário de terras, no contexto em que a parte arrendadora seja um agricultor patronal ou empreendimento empresarial. Nessa situação, as percepções mudam, pois o contrato de arrendamento com agricultores patronais ou empresários agrícolas (categorias sociais diferentes) tem por pano de fundo as diferenças sociais e de recursos entre arrendador e arrendatário. Isso reforça a importância das similitudes (econômicas e culturais, como vimos no tópico acima) para os arrendamentos rurais entre agricultores familiares.

A maior parte dos agricultores familiares oferece garantias contratuais imateriais (reputação pública e ligações familiares) ou, quando muito, pequenos imóveis/máquinas que não sejam essenciais à sobrevivência da família. Os entrevistados do subgrupo 1 (agricultores familiares) e do subgrupo 3 (categoria social não familiar) são unânimes em relatar que os agricultores familiares não podem oferecer a segurança contratual exigida nos contratos firmados com agricultores patronais, não só pela limitação de seus recursos, mas pela alta competitividade local.

A existência de empreendedores rurais interessados em arrendar, oferecendo fortes garantias reais (imóveis, terras, direitos) e operacionais (experiência com porte institucional e infraestrutura especializada) reafirma o aspecto discursivo já citado, de que os agricultores familiares entrevistados percebem os arrendamentos rurais

\footnotetext{
Essa similaridade leva em conta também a composição da paisagem, incluindo a noção estética, contemplativa, e mesmo bucólica, do ambiente rural como um espaço de relativa harmonia com a natureza. Conta ainda haver possibilidade de cultivos da área originária serem levados às áreas arrendadas, com aproveitamento de mão de obra e experiência da família, além de gerar a continuidade das áreas. Outro fator relevante é haver experiência anterior com a prática contratual, especialmente no histórico familiar (pais e avós) ou de amigos próximos, que tornem a prática mais referenciada para a família. Essa partilha de informações e experiências acaba levando muitos arrendamentos a uma grande diversidade de regras formais e informais (divisão de trabalho e produtos, empréstimo condicional de máquinas, modificação de cultivo, alteração superveniente de prazos para além das previsões legais, disposição de benfeitorias) que geram formas híbridas.
} 
em Rio Verde como "contratos para agricultores ricos". À medida que se torna uma prática cada vez mais concentrada em categorias sociais detentoras de capital, terra e informação, os agricultores familiares apresentam uma baixa expectativa sobre a concretização desses contratos com outras categorias sociais.

Por outro lado, devem-se considerar também fatores determinantes na situação em que o agricultor familiar (como arrendador de terras) contrata com outro agricultor familiar, este na condição de parte arrendatária. Nesse caso, os vínculos afetivos e sociais entre arrendante e arrendatário continuam importantes. Embora as garantias reais (imóveis, máquinas e direitos) sejam significativas, é a reputação pública (senso de honradez) do agricultor na comunidade que deflagra todo o processo de negociação ou de negativa do arrendamento.

As histórias de família, a tradição no local, o tempo de moradia, o cumprimento de contratos anteriores e as consultas cartoriais simples são meios para captação de informações sobre a viabilidade do contrato. A proximidade física das glebas também interfere, pois permite a fiscalização do uso das terras, bem como das relações de compadrio que, naturalmente, são mais fortalecidas (trazendo formas adicionais de colaboração, através de empréstimo de máquinas, planejamento de cultivos, acesso a transporte, compras conjuntas, etc.). Por extensão, a identidade ou similaridade na gestão da propriedade é um fator determinante, pois diminui o desgaste dos recursos produtivos e preserva a paisagem anterior (o que inclui combinados sobre a preservação de tal árvore centenária, não desfazer determinado pomar, evitar que o gado atravesse o curso de água, etc.).

Dentre os polos contratuais possíveis, é possível o agricultor familiar como um arrendador de terras, no contexto em que a parte arrendatária seja um agricultor patronal ou empreendimento empresarial. Nessa configuração, de acordo com os dados de campo, os elementos discursivos mudam profundamente.

Os agricultores mais descapitalizados (subgrupo 2) identificaram o arrendamento rural como uma forma positiva de se capitalizarem, bem como de sobreviverem através da renda, obtendo recursos para moradia, alimentação, saúde, sem o ônus do trabalho no meio rural. Nesse sentido, sua intenção é a cessão da terra através de contrato formal, que garanta basicamente o retorno da propriedade e o valor da renda em dinheiro. A lógica subjacente é a de obter o pagamento de renda, superior à receita ou à subsistência gerada pela propriedade. 
Por outro lado, os demais agricultores familiares (aqueles que produzem o suficiente para subsistência e/ou para comercializar excedentes) manifestaram resistência a arrendar suas terras para um arrendador da agricultura patronal ou empreendimento empresarial. Nesse sentido, diversos fatores desestimulariam esses tipos de arrendamentos.

O primeiro seria o temor de perder a terra para o arrendatário patronal ou empresarial, por razões ligadas às diferenças de poder econômico e político entre as partes. Há também receio de que o arrendamento possa gerar a infertilidade das terras por práticas da monocultura, comuns em Rio Verde. A possibilidade de indenização posterior não os convence do contrário, pois a morosidade da Justiça e os gastos processuais desestimulam a solução jurídica da situação. A esse fator se soma o temor de que o arrendamento possa inviabilizar a diversidade de produção nas suas terras, pela implantação de ativos altamente específicos (silos, planagens, galpões, barragens). Não se pode negar que a insegurança em relação à moradia $\mathrm{e}$ ao sustento da família, em outra atividade, desestimula a possibilidade de deixar aquela residência e estilo de vida, como arrendadores. Embora relatem grandes dificuldades, os agricultores familiares manifestam prazer pela forma de vida rural (contato com a paisagem natural, os ciclos agrários, a vizinhança, animais de estimação, criações mantidas há anos, etc.).

Em todas essas configurações contratuais, o arrendamento rural praticado pelos agricultores familiares é altamente peculiar, pois não corresponde exatamente à prática descrita no Estatuto da Terra. $\mathrm{O}$ caráter híbrido, informal e tendente à parceria desses contratos é um atributo do agricultor familiar, enquanto fruto de sua imensa capacidade de criar e improvisar (babitus). Mas, é também uma necessidade, enquanto estratégia de resistência à competitividade e seletividade do mercado de arrendamentos em Rio Verde.

Um dos resultados obtidos na pesquisa é que grande parte dos entrevistados (agricultores familiares) arrendariam terras entre si (parentes, amigos, vizinhos) por motivações e finalidades das mais diversas (oriundas das dimensões teleológica, legal e sociocultural), tais como o afeto pela terra, o gosto pelo contato com a natureza, a fé em Deus, a vontade de unir os filhos, a luta por ideais políticos, o sentimento de honra objetiva e subjetiva, etc. 
Essa capacidade de improvisação não é somente um desdobramento de sua criatividade. A necessidade de sobreviver, lutar e criar vias alternativas contra bloqueios faz surgir uma teia de contratos, onde o arrendamento não é um contrato autônomo (por si), mas está em função de cláusulas extracontratuais, baseadas em relações afetivas (familiares e comunitárias). Os serviços trocados, a partilha dos riscos e a fixação de prazos, por exemplo, passam ao largo da legislação, como estratégias ao alto custo da formalização/adequação dos contratos e seus serviços jurídico-cartoriais, às dificuldades de aquisição dos insumos e maquinários, às restrições de crédito e informação. Essa dinâmica faz com que o arrendamento rural seja percebido (representado) pelos agricultores familiares, e praticado por outras categorias sociais, como um contrato de finalidade altamente mercantil, nos empreendimentos que tem, por base, o trabalho assalariado e, por prioridade, a maximização do lucro (CASTRO, 2013).

Nas entrevistas realizadas fica muito claro que a concentração dos arrendamentos nas categorias sociais tidas como "empresários agrícolas" tem por pano de fundo a desigual distribuição de recursos no campo, mantendo-se como um contrato adequado ao modelo agroexportador, monocultor e que, como os próprios entrevistados observaram, tende a se tornar arrendatário de vastas áreas. Isto é, o arrendamento formal e estável restringe-se a categorias sociais que já possuem capital, tecnologia e informação e, por isso, acessam cada vez mais terras por via contratual (CASTRO, 2013).

\section{CONSIDERAÇÕES FINAIS}

A presente pesquisa, tendo por fio condutor a concepção de "Habitus" (BOURDIEU, 2008b), analisou os elementos condicionantes dos arrendamentos rurais na Agricultura Familiar brasileira. Foram considerados os discursos e narrativas de 20 (vinte) agricultores oriundos de diversas categorias sociais, residentes em Rio Verde (GO). As entrevistas em profundidade viabilizaram materiais sobre como os elementos econômicos e sociais que condicionam de forma mais genérica os contratos agrários se relacionam e influenciam a formação dos arrendamentos. 
A partir disso, a dinâmica do "Habitus" foi interpretada segundo dimensões e lógicas do processo decisório, confirmando a hipótese de que a opção sobre arrendar ou não as terras é mais que uma opção jurídica ou econômica, devendo ser tratada como parte de um processo social de múltiplas dimensões. Nesse sentido, a desigual distribuição de capital, informação e terras, em última instância, impede que o arrendamento se torne uma prática contratual democrática, acessível e equilibrada. Nos relatos dos entrevistados, percebe-se que o arrendamento rural não é praticado entre categorias diferentes, por ser visto com descrença ou temor, pois, muitos acordos, sob a pressão de imperativos econômicos, não atendem ao significado teleológico, legal e sociocultural que os agricultores familiares entrevistados atribuem às coisas da vida, configurando-se como uma verdadeira violência (acesso espoliativo a suas terras).

Aspectos das dimensões teleológica, legal e sociocultural, ante à realidade de Rio Verde, levam os agricultores familiares entrevistados a resistir ao arrendamento rural (especialmente a se tornarem arrendatários para outras categorias sociais). Exemplo disso é o receio quanto ao deslocamento geográfico, pois percebem como suas terras são progressivamente arrendadas nas proximidades das plantações de cana-de-açúcar, sorgo, soja e outros cultivos. Para eles, tais áreas deixam de ser um "pedaço de terra", isto é, deixam de ser espaço de convívio comunitário para formar uma "imensidão contínua das plantações". Perde-se o lugar de trabalho, de moradia, de cidadania, de vida para suas famílias (CASTRO, 2013).

Os dados das entrevistas em profundidade permitiram identificar uma combinação reflexiva e multidirecional de fatores políticos, sociais, culturais, jurídicos e econômicos, como parte das dimensões e lógicas decorrentes do "habitus", que merecem novas e mais profundas pesquisas. Por esse caminho, o arrendamento rural é uma prática rejeitada pelos agricultores familiares entrevistados, no Sudoeste de Goiás. Além da ideia de que o grande empresário agrícola é quem realmente se beneficia (arrendatário de grandes áreas para cultivos comerciais), é percebido (e vivido) como símbolo, instrumento e lugar de exclusão social e marginalização política.

Por fim, quanto às avenidas de pesquisa, estudos futuros devem investigar a atuação de outros agentes no processo decisório do agricultor familiar, a exemplo 
dos investidores rurais, que atuam como arrendatários. A forma como se colocam nas relações (entre agricultores familiares e empresários agrícolas), bem como sua relevância na dinâmica decisória, permitem uma melhor compreensão sobre a formação dos arrendamentos rurais a partir da interação de seus diferentes atores. Tais questões lançam novos elementos ao debate, como a percepção da terra diante de outros ativos financeiros, o caráter especulativo (expectativa da valorização de preço) e ingerências no processo de territorialização e pertencimento ao território, relevantes no diálogo das dimensões teleológica, legal e sociocultural.

\section{REFERÊNCIAS}

ALMEIDA, P. J. de. A Evolução do arrendamento de terras na região do triângulo mineiro. Uberlândia: DEECO/UFU. (Monografia). 1999.

ALMEIDA, P. J. de. Arrendamento e acesso à terra no Brasil. 2002. Dissertação (Mestrado) - IE/UNICAMP, Campinas, 2002.

BAIARDI, A. Formas de agricultura familiar, à luz dos imperativos de desenvolvimento sustentável e de inserção no mercado internacional. Foz do Iguaçu: SOBER, 1999.

BOURDIEU, P. A economia das trocas simbólicas. 6. ed. São Paulo: Perspectiva, 2009.

BOURDIEU, P.; WACQUANT, L. An Invitation to reflexive sociology. Chicago: University of Chicago Press; Cambridge: Polity, 1992. BOURDIEU, P.; WACQUANT, L. O poder simbólico. Lisboa: Difel, 1989b.

BOURDIEU, P. A distinção: crítica social do julgamento. São Paulo: EDUSP, 2008b.

BOURDIEU, P.; WACQUANT, L. Pierre Bourdieu avec Löic Wacquant: réponses. Paris: Seuil, 1992.

BOURDIEU, P. Razóes práticas: sobre a teoria da ação. Campinas: Papirus, 2008a. 
BRANDEMBURG, A.; FERREIRA, A. (Org.). Para pensar outra agricultura. Curitiba: Ed. da UFPR, 1999.

BRANDEMBURG, A.; FERREIRA, A. Agricultura familiar, ONGs e desenvolvimento sustentável. Curitiba: Ed. da UFPR, 1999.

BRASIL. Código Civil e legislações ordinárias. Disponíveis em: <www. planalto. gov.br/ccivil_03/LEIS > . Acesso em: 10 maio. 2014.

CASTRO, L. F. P. Agricultura familiar, habitus e acesso à terra. Revista Brasileira de Sociologia do Direito, v. 2, p. 91-105. 2015a.

CASTRO, L. F. P. Arrendamentos rurais na agricultura familiar: habitus, direito e acesso à terra. Revista Científica Semana Acadêmica, Fortaleza, v. 1, n. 77, p. $1-15,2015 b$.

CATANI, A. M. Espaço social e espaço simbólico: introdução a uma topologia social. Perspectiva, Florianópolis, v. 20, 2002.

CASTRO, L. F. P. Dimensóes e lógicas do arrendamento rural na agricultura familiar. 2013. Dissertação (Mestrado) - PROPAGA/UNB, Brasília, 2013.

CASTRO, L. F. P.; SAUER, S. A Problemática e as condicionantes dos arrendamentos rurais na agricultura familiar. Vitória: SOBER, 2012.

CHALITA, M. A. N. Agricultura familiar na citricultura paulista: a reconstituição da trajetória de um conceito. Ribeirão Preto: SOBER, 2005b.

CHALITA, M. A. N. Desenvolvimento rural, agricultura e natureza: novas questões de pesquisa. São Paulo, Secretaria de Agricultura, 2005 a.

FAO/INCRA, GUANZIROLI, C. E.; CARDIM, S. C. S. (Coord..) Novo retrato da agricultura familiar: o Brasil redescoberto. Brasília: FAO/INCRA, 2000.

FERREIRA, A. Agricultores e agroindústrias: estratégias, adaptações e conflitos. Revista da Associação Brasileira de Reforma Agrária, v. 25. 1995. 
FERREIRA, A. Redes sociais, penosidade física e moral: o ocultamento como face das estratégias de reprodução social dos agricultores familiares em Áreas de Proteção Ambiental. In: CONGRESSO DA ASSOCIAÇÃO LATINO-AMERICANA DE SOCIOLOGIA RURAL, 6., 2002. Anais... UFRGS, 2002.

FERREIRA, I. C. B. Ceres e Rio Verde: dois momentos no processo de expansão da fronteira agrícola. In: AUBERTIN, C. (Org.). Fronteiras. Brasília: UnB; Paris, ORSTOM, 1988.

FETAEG - Federação dos Trabalhadores na Agricultura do Estado de Goiás. Relatório sobre Rio Verde/GO. 2002.

FRANÇA, C. G.; DEL GROSSI, M. E.; MARQUES, V. P. M. A. O censo agropecuário 2006 e a agricultura familiar no Brasil. MDA. Brasília. 2009.

IBGE. Censo Agropecuário 2006: Brasil, Grandes Regiões e Unidades da Federação. Rio de Janeiro, 2007.

IBGE. Censo Agropecuário 1920 to 1995/96. Rio de Janeiro. (Séries Estatísticas \& Séries Históricas). Disponível em: <http:www.ibge.gov.br/series_estatisticas/ subtema.php?idsubtema $=100>$. Acesso em:

INCRA/FAO. Novo retrato da agricultura: o Brasil redescoberto. Brasília: MDA, 2000.

INCRA/FAO. Perfil da Agricultura Familiar no Brasil: dossiê estatístico. Brasília: 1996.

LAMARCHE, H. (Coord.). A agricultura familiar. Campinas: Unicamp, 1997. v. 1; 2.

LAMARCHE, H. A agricultura familiar: comparação internacional. Tradução de Ângela Maria NaokoTijiwa. Campinas: Ed. da UNICAMP, 1993.

LAMARCHE, H. Hugues. (Coord.) L'agriculturefamiliale. 1. Une réalité polymorphe. Paris, L'Harmattan, 1993. 2. Du mythe à laréalité. Paris, L'Harmattan. 1994. 
MARCONI, M. A.; LAKATOS, E. M. Fundamentos de metodologia científica. São Paulo: Editora Atlas, 2005.

NEVES, D. A agricultura familiar: questões metodológicas. Revista Reforma Agrária, Campinas, v. 25, p. 21-37, maio/dez. 1995.

PAULILO, M. Produtor e agro-indústria: consensos e dissensos. O caso de Santa Catarina. Florianópolis: UFSC, 1990.

SAUER, S. A luta pela terra e a reinvenção do rural. In: CONGRESSO BRASILEIRO DE SOCIOLOGIA, 11., 2003. Anais...

SAUER, S. Agricultura familiar versus agronegócio: a dinâmica sociopolítica do campo brasileiro. Brasília: Embrapa, 2008.

WANDERLEY, M. Agricultura familiar e campesinato: rupturas e continuidades. In: WANDERLEY, M. N. B. O mundo rural como espaço de vida: reflexões sobre a propriedade da terra, agricultura familiar e ruralidade. Porto Alegre: UFRGS. 2009a.

WANDERLEY, M. O agricultor familiar no Brasil: um ator social da construção do futuro. Revista Agriculturas: experiências em Agroecologia, Rio de Janeiro, 2009b.

WANDERLEY, M. Raízes históricas do campesinato brasileiro. In: TEDESCO, João Carlos (Org.). Agricultura familiar: realidades e perspectivas. Passo Fundo, 1999.

Recebido em: 13 de dezembro de 2015 Aceito em: 23 de abril de 2016 